\title{
The Change from "Teaching" to "Learning"___Awareness and Reflection on "Student-centered" Education
}

\author{
Chunhui Pan \\ Shaanxi Institute of International Trade \&Commerce, Xianyang, Shaanxi, 712046
}

Keywords: Student-centered; concept; connotation; understanding; thinking

\begin{abstract}
At present, there is a phenomenon that students do not love learning, do not learn, and learn badly. The problem of students' learning directly affects the quality of personnel training. Although the problem is expressed in students, the roots are in the educational concept for many years, which comes to the change of "teaching" to "learning". Only by establishing a "student-centered" educational philosophy can we solve this problem from the root cause. How is it for "student-centered" in the context of the popularization of higher education? Recognize, interpret, clarify the connotation of "student-centered", and have an accurate understanding of the concept is important to correctly apply this concept in teaching practice to guide teaching and solve problems in teaching.
\end{abstract}

\section{Introduction}

At present, teachers in our teaching are generally confused about the style of study. The specific performance is that many students "do not love learning, they will not learn, and they will not learn well". The so-called "do not love learning" means that the interest in learning is not strong, the motivation for learning is insufficient, and therefore it is impossible to take the initiative to learn, so that it is tired of learning, frequently skipping classes, and even dropping out of school; and "not learning" is mainly due to improper learning methods. Nothing is right, half the effort, pay a lot, and the effect is very small. Therefore, "will not learn" leads to more "do not love learning", resulting in a vicious circle. The result is necessarily poor learning, weak learning ability and poor learning effect. In this way, a healthy and healthy study style will be difficult to form.

The problems in student learning directly affect the quality of talent development. The reasons are various, including the weakness of ideological education, etc., but the author believes that the problem lies in the students, the root lies in our educational philosophy, and lies in the teaching paradigm we choose and implement. This is the main reason for the current problem of learning style. For many years, we have been teaching the word "teaching", focusing on "teaching" and "learning". The foothold is the teacher's "teaching" and the ignorance of the students' "learning". This traditional teaching closely surrounds the protagonist of the teacher. Called the "teacher-centered" teaching paradigm, its three major elements are teachers, textbooks, and classrooms. As a result, the true protagonist "student" is missing. The result is the evolution of university teaching into "teacher teaching materials, students." Back textbooks, exam textbooks." In the long run, the formation of a healthy and good study style will gradually drift away, and the quality of teaching will be difficult to guarantee. Therefore, we must reform the traditional teaching paradigm, establish a new concept of "taking student learning as the center, learning effect as the center, and taking student development as the center", and construct a new "teacher-centered" teaching paradigm. It is the fundamental way to change the style of study and improve the quality of teaching.

How to correctly understand the "student-centered" connotation, and can be truly implemented in our teaching and management, this article from two aspects, namely: "student-centered" is what, "student-centered" Not what, talk about personal knowledge and opinions. 


\section{The "Student-centered" Concept}

In a college, there are only three types of relationships with students: one is the relationship between the school and the students; the other is the relationship between the teacher and the student; the third is the relationship between the manager and the student. Let me start with these three types of relationships and analyze what is "student-centered."

First, the school must be centered on the growth of students. Then we must first consider what is the mission of the school? There are many references to the school's mission, such as the role of society, the public's conscience, and the cultural center. We can also think about it from another angle. Why does it exist as a university for a long time? The only answer that can stand the test is because students, no students, can't exist in this university, that is, research institutes. Students are the only reason why universities exist. Then, according to this idea, we can have many phenomena existing in the current university, such as the construction of quality engineering, the construction of teachers, the good ranking of schools, the acquisition of key disciplines, research platforms, major achievements rewards, etc. Going back to our original intentions and rethinking, what are the starting points for all these projects and the efforts to achieve these iconic results? Have you considered students? How much do students grow into talents from these projects and outcomes? If these projects and iconic achievements can truly take students' growth into talents, they will be really useful for the quality of the school's training, useful for improving the reputation of the school, and useful for the sustainable development of the school.

Second, schools should be centered on teaching, and teaching should be centered on students. At present, "teaching is the center" has a lot of knowledge, but it is familiar, but "teaching-centered" can definitely represent "student-centered"? That is not necessarily the case. The author's understanding, the so-called "teaching-centered", at the school level should be carried out in the five aspects of leadership energy, resource allocation, work arrangement, funding ratio, team building, etc. Under the premise, the policies we have developed to improve teaching and student learning, and the relevant policies, only reflect the concept of student-oriented, and fully consider the differences in students' individuality and development needs, so that students can benefit from it. This is The original intention and the true purpose of "teaching as the center".

Third, schools must create good conditions for students to grow up. Including our laboratories should be open to students, especially professional laboratories and research laboratories. The library is rich in resources and needs to provide humanized services. The school's sports facilities should be sufficient to meet the needs of students and to serve students carefully. The campus environment should be neat and beautiful. It is necessary to create a calm atmosphere for students to learn, so that when students enter the campus, they can feel the strong academic and learning atmosphere of colleges and universities.

As mentioned above, our traditional education has a third center: teacher-centered,

Centered on the textbooks and centered on the classroom. We now say that "student-centered" should establish the subjective status of students in teaching. So, what is the role of the teacher in the new teaching paradigm? Especially now entering the era of network information, many of our teachers have not yet considered and fully understood the changes brought about by the age of network information. Their own personalities, including personal life, have already entered the Internet age, and the teaching philosophy, Teaching methods are still in the past, and how can the traditional teaching paradigm adapt to the needs of active students and new social needs. We should all think about facing a new era, as teachers should face in the classroom. In order to express my thoughts more clearly, for a simple example, for example, we often see some teachers in the classroom to break the contents of the textbooks, smashing them, cumbersome and tireless from the beginning to the end. However, the content of the lectures is easy for students to use on the Internet, and the amount of information is not only richer and more comprehensive than the materials taught by the teacher, but also updated. Then how much more can you say about this, how much interest students can have for you. As a teacher, we must think about how to change the traditional teaching mode and cultivate and enhance students' independent learning ability in the face of the new 
information age. Here is a question of repositioning the teacher's role. For students, teachers are no longer the only source of knowledge. In the classroom, this "on-the-spot" teacher is no longer "starring", but "director", no longer "central, authoritative", but should be the student's "instructor, helper, senior partner." In the face of this role change, teachers are not doing less than before, but doing more, spending more thoughts, investing more energy, focusing on "learning", design and innovation. The "student-centered" teaching method explores the content of "behind" teaching materials, creates a learning atmosphere of interaction between teachers and students, and interacts with students. It is necessary to carry out team learning, cooperative learning and research-based learning to cultivate students' innovative consciousness and debate. thinking ability. The change of the "student-centered" teaching paradigm is not only the reform of teaching methods, but also the reform of the evaluation of teaching quality. The reform of the assessment of students' academic performance is a comprehensive reform of teaching work.

The "student-centered" embodiment of the school is "to educate people as the center". Make

For a university to educate all members, it means that every employee is a teacher regardless of his position. Although he is not necessarily a teacher of professional knowledge, he can be a teacher of morality, a teacher of being a teacher, and a teacher of doing things. Executives, counselors, teaching assistants, and logistics personnel are responsible for educating people. In addition to the quality of service, each functional department should emphasize that the policies introduced should be conducive to the growth of students, not just to their own management. At present, some of the policy considerations introduced by the school are mostly based on the convenience of their own management, and less can be considered from how to benefit the development of students.

\section{Problems in "Student-centered" Concept}

Establish a "student-centered" philosophy, and figure out what the student-centered connotation is. It also needs to clarify what it is not, and avoid another wrong tendency that will appear in our thinking.

Some teachers and administrators have a misunderstanding of "student-centered". They believe that to be student-centered, all the requirements put forward by students should be met. When some students have difficulty learning, they can lower the requirements of the course at will. Relocate students. This is a serious misinterpretation of the "student-centered" philosophy. If we reduce the teaching requirements and reduce the difficulty of learning to meet the requirements of students, it is actually a serious irresponsibility for students to learn, not for students, but for students. In this case, what we should do is to provide students with targeted help and guidance in taking into account the factors of student learning differences and personality differences.

Some teachers may suggest that since the students are the center, the teacher can still ask for the requirements and dare to manage the students. I think that "student-centered" is by no means a standard reduction, nor a relaxation of management, and it is not a laissez-faire to students. Instead, it is necessary to pay more attention to the students, and to ask the students more rigorously, because the students are in the immature stage of development, especially many students have not developed the habit of active learning, which requires teachers and Managers strictly demand their behavior when they have errors and poor performance, helping and guiding them to develop good learning and behavioral habits.

Other teachers will think that "student-centered" means that students like to listen to what I am talking about. If students are not interested, I will not talk about it. And I think that "student-centered" is not simply to please students according to their hobbies and interests. In the classroom, only students love to listen, and professional training objectives are ignored. The curriculum requirements and knowledge are scientific and systematic. Higher education is a professional education. Each major is designed with scientific training objectives and graduation requirements. According to social needs and employment needs, a curriculum system that meets graduation requirements is constructed. Qualified graduates should have certain knowledge, quality and ability. Our students, the logic system of their knowledge has not yet been established, and they do not understand the systematic nature of professional knowledge. Sometimes they simply start 
from the personal interests and hobbies and blindly and selectively absorb knowledge. In this case, if you simply cut down the content of the teaching according to the personal preference of the students, it will seriously affect the achievement of the goal of educating people. In the long run, it is not student-centered, but harms the students and delays the students. What the teacher should do is to stimulate and protect the students' interest in learning. On the one hand, they should take a good introduction to the professional, so that students have a comprehensive understanding of the majors they have studied, and help students plan their own studies. On the other hand, in the course teaching, the concept of "student-centered" is established, focusing on the cultivation of students' learning ability and the cultivation of self-learning habits, and giving students more precise and effective guidance and help in learning methods.

We can only apply this concept to our teaching reforms and implement them in our management process only if we understand what is "student-centered" and not what it is. In this long-term persistence, the universities we run will certainly be loved and recognized by the students, and the schools will truly cultivate outstanding talents with the ability to have the ability to be responsible for the society.

\section{References}

[1] Liu Xianjun. On "Student-centered"[J]. Research of Higher Education, 2012, 33(8):1-6

[2] Wang Hongcai. What is “student-centrism”? [J]. University Education Science, 2014 (6): 62-66

[3] Li Peigen. Student-centered education—an important strategic shift [J]. China Higher Education, 2011 (Z2): 8-9

[4] Zhu Xin. Historical Review and Value Orientation of the "Student-centered" Education Concept [J]. Modern Education Management, 2012(4): 6-9 